\title{
Aeroelastic Control of Oblique-Wing Aircraft
}

John J. Burken, Gurbux S. Alag, and Glenn B. Gilyard

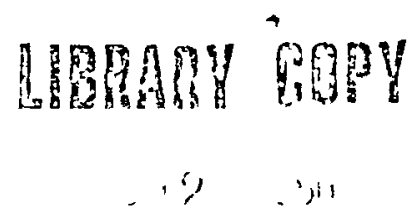

LANGLEY FESEARCH CENTER LIRRARY, NASA HA:PTON, VIRGINIA 
31176013086716 
NASA Technical Memorandum, 86808

\section{Aeroelastic Control of Oblique-Wing Aircraft}

John J Burken

Ames Research Center, Dryden Flight Research Facility, Edwards, California

Gurbux S Alag

Western Michigan University, Kalamazoo, Michigan

Glenn B Gilyard

Ames Research Center, Dryden Flight Research Facility, Edwards, Californı 
AEROELASTIC CONTROL OF OBLIQUE-WING AIRCRAFT

John J. Burken*

NASA Ames Research Center Dryden Flight Research Facility Edwards, California

Gurbux S. Alag**

Western Michigan University Kalamazoo, Michigan

Glenn B. Gilyard*

NASA Ames Research Center Dryden Flight Research Facility Edwards, California
ABSTRACT

The U.S. Navy and NASA are currently involved in the design and development of an unsymmetricskew-wing aircraft capable of $65^{\circ}$ wing sweep and flight at Mach 1.6. A generic skew-wing aircraft model was developed for $45^{\circ}$ wing skew at a flight condition of Mach 0.70 and $3048 \mathrm{~m}$ altitude. At this flight condition the aircraft has a wing flutter mode. An active implementable control law was developed using the linear quadratic Gaussian design technique. A method of modal residualiza$t i o n$ was used to reduce the order of the controller used for flutter suppression.

SYMBOLS
A

$A_{1}$

$\vec{A}, \vec{B}, \vec{C}, \vec{D} \quad$ reduced-order controller statespace matrices

$B_{1}, B_{2}$

$B_{11}, B_{21}$

$b_{\ell}$

C

$c_{1}, c_{2}$

0

$F(s)$

plant matrix

coefficient matrices of unsteady aerodynamic force approximation

ontrol and noise distribution matrices, respectively

modal system input matrices corresponding to the low- and high-frequency parts of $\Lambda$

lag coefficients

state-space output matrix

modal system output matrices corresponding to the low- and high-frequency parts of $\Lambda$

generalized damping matrix

* Aerospace Engineer.

* Associate Professor, Electrical

Engrneering Department.

This paper is declared a work of the US Government and therefore is in the public domain

\section{$f(t)$}

J

$k$

$L, L_{1}$

M

$P_{J}$

$Q$

$Q(s)$

$Q^{1 j}(s)$

$q$

R

s

$T$

$u$

$u_{c}$

$v_{g}$

$x, \hat{x}$

y

$z_{1}$

$\delta_{\mathrm{a}}, \delta_{\mathrm{ac}}$

$\eta$ forcing function in time domain

quadratic cost criterion

regulator gain matrix, or generalized stiffness matrix

robust and ordinary Kalman estimator gain matrices, respectively

generalized mass matrix

pressure distribution of the Jth mode

state weighting matrix

matrix of approximated aerodynainic force coefficients

the $(i, j)$ element of a matrix of functions due to a mode

vector of generalızed coordinates

control weighting matrix

Laplace operator

modal matrix

1nput vector

controlier output

gust velocity

state vector and estimated state vector, respectively

output vector

mode shape of the ith mode

control surface deflection and surface comand, respectively

random white noise excitation 


$\sigma$
$\sigma$
$\Lambda$
$\Lambda_{1}, \Lambda_{2}$
$\omega_{g}$
$\omega_{m}$

gust calibration factor

minimum singular values of the return difference matrix

similarity transform matrix

low- and high-frequency parts of $\Lambda$, respectively

wing gust input

zero-mean white noise errors in the measurements

\section{INTRODUCTION}

Interest in oblique-wing aircraft designs has surfaced periodically since the 1940s. However, not until recently has the interest, technology, and mission of an oblique-wing design evolved into a full-scale flight research program. The U.S. Navy and NASA are currently in the design and development stage of implementing an oblique wing on an F-8 fuselage ( $F i g .1)$ and evaluating the configuration to a maximum sweep of $65^{\circ}$ and to Mach 1.6.

The unsymmetric configuration and forward sweep of one semispan result in aeroelastic behavior distinctly different than that of straight, swept-back, or swept-forward wings. It should be noted that in addition to unsymmetric modeling characteristics, unsymmetric configurations will typically have significantly larger plant formulations since all degrees of freedom must be adequately represented. Separation of an unsymmetric model into two smaller models (as is possible for symmetric and antisymmetric modes of a symmetric alrcraft) is not possible, because the response motion is coupled and not separable.

To evaluate the analytical tools required for the analysis of an oblique-wing configuration, a generic skewed-wing model was developed. This model was used for the control system synthesis procedure described in this paper. The configuration selected has a wing skew of $45^{\circ}$ at a flight condition of Mach 0.70 and $3048 \mathrm{~m}$ altitude (a dynamic pressure of $23,892 \mathrm{~N} / \mathrm{m}^{2}$ ).

This paper demonstrates the control synthesis design process required to develop a practical control law for stabilization of the flutter mode. This process involves

1. formulation of the state-space model including independent wing actuators, a Dryden gust model [1], and s-plane approximations of unsteady aerodynamics;

2. optimal full-state control law determination;
3. robust output feedback control law determination;

4. reduced-order (practical) control law formulation; and

5. evaluation of the practical control law.

\section{MATHEMATICAL MODELS}

\section{Aircraft Model}

The generic oblique-wing aircraft model used in the system synthesis process consists of a simple beam representation of the fuselage and wing. The structural model and the aerodynamic paneling required for the unsteady aerodynamics are represented in Fig. 2 .

The aircraft modal characteristics were developed using NASTRAN analysis. At the selected sweep configuration $\left(45^{\circ}\right)$ and flight conditions (Mach 0.70, $3048 \mathrm{~m}$ altitude), the unaugmented alrcraft has a flutter mode characterized as primarily wing bending but with some torsion. The in-vacuum mode shape characteristics of the wing alone are presented in $F_{1 g} .3$ for the mode that is driven to the flutter condition with increasing dynamic pressure.

Because the intent of this paper is to present a design synthesis process, the model order was reduced considerably; the final model contained a rigid-body (primarily pitch) mode along with three elastic modes. The model reduction process did not significantly affect the flutter mode characteristics.

The formulation of the complete, integrated (structures, aerodynamcs, and controls) statespace model for use in the analysis and design process follows that of Peele and Adams [2]. The aeroelastic equations of motion for the flexible aircraft can then be represented as

$$
M q+D \dot{q}+K q=f(t)
$$

where the matrices $M, D$, and $K$ are the generalized mass, damping, and stiffness matrices, respectively, $q$ is the vector of generalized coordinates, and $f(t)$ is the vector of unsteady aerodynamic forces; the dots denote differentiation. Transforming to the Laplace domain yields

$$
\left(M s^{2}+D s+K\right) q(s)=F(s)
$$

where $s$ is the Laplace operator and $F(s)$ is the aerodynamic forcing function in the $s$ plane. The unsteady aerodynamic forces can be expressed as

$$
F(s)=Q(s) q(s)
$$


where the matrix $Q(s)$ contains the generalized aerodynamic force coefficients. The individual elements of $Q(s)$ are functions of both aircraft mode shapes and pressure changes resulting from motion in the various modes. The elements are defined as

$$
Q_{1 J}(s)=\iint_{S} z_{1}(x, y) p_{J}(x, y, s) d S
$$

where $z_{1}(x, y)$ is the mode shape of the ith mode and $p_{j}(x, y, s)$ is the pressure distribution of the Jth reduced frequency determined from a lifting surface theory. Under the subsonic conditions relevant to this study, the unsteady aerodynamic force coefficients (elements of $Q$ ) were computed using the doublet lattice routine contained in the ISAC program $[2,3]$. Eight reduced frequencies were used, covering the range of 0 to $1.2 \mathrm{rad} / \mathrm{sec}$. However, this procedure yields aerodynamic forces only for pure harmonic motion, and therefore only a finite number of frequencies can be selected. As a result, tabulated aerodynamic forces are expressed as a function of frequency. To appiy modern control techniques, the tabulated aerodynamics must be expressed in state-space form. If analytic continuity is assumed, the aerodynamic data can be expressed as a rational function approximation [4], such as,

$$
Q(s)=A_{0}+A_{1} s+A_{2} s^{2}+\sum_{\ell=1}^{n} A_{\ell+2}\left[s /\left(s+b_{\ell}\right)\right]
$$

where $A_{0}$ to $A_{n+2}$ are coefficient matrices of unsteady aerodynamic force and $b_{\ell}$ are "lag" coefficients. A least squares approach can then be used to determine the matrices $A_{0}, A_{1}, A_{2}, \ldots$, $A_{n+2}$. The lag coefficients $b_{1}, b_{2}, \ldots, b_{n}$ are selected specifically for the analysis; the number of lag terms and their values are important in obtaining good approximations of the tabulated aerodynamics. In the oblique-wing design model described in this paper, two lag terms were used in generating the s-plane fit of the unsteady aerodynamics. A typical fit of the approximation to the tabulated data for one element of the $Q(s)$ matrix is presented in Fig. 4.

\section{Actuator Model}

Left and right wing actuators were modeled independently because the synthesis process determines unique control laws for each surface. The following third-order model relates the control surface deflection $\delta_{a}$ to the control surface command $\delta_{a_{c}}$

$$
\frac{\delta_{a}}{\delta_{a_{c}}}=\frac{54,080}{(s+20)\left[s^{2}+2(0.7) 52 s+52^{2}\right]}
$$

It is assumed that the actuators have sufficlent power throughout the frequency range of interest and that aerodynamic hinge moments and inertial cross coupling do not affect control surface position.

\section{Gust Model}

The following second-order Dryden gust model [1] was also incorporated in the mathematical model:

$$
\frac{v_{g}}{n}=\sigma \frac{0.273(1+4.114 s)}{(s+0.421)^{2}}
$$

where $n$ is random excitation, $\sigma$ is used to calibrate the gust intensity (to $1 \mathrm{ft} / \mathrm{sec}$ in the current example), and $v_{g}$ is the output gust velocity.

\section{State-Space Equations}

The design model is obtarned by combining the aircraft (including the linearized form of the unsteady aerodynamics), the actuators, and the gust model dynamics and can be represented in the state-space equation form as

$$
\begin{aligned}
& \dot{x}=A x+B_{1} u+B_{2} w_{y} \\
& y=C x+4 m
\end{aligned}
$$

where $x$ is the state vector, wy the wing gust input (unit white norse), wn the measurement nolse, $u$ the control input vector $(2 \times 1)$, and $y$ the measurement vector $(3 \times 1) ; A, B_{1}, B_{2}$, and $C$ are plant equation, control, noise distribution, and state-space output matrices, respectively, of suitable dimensions. The state vector contains 24 states, including the rigid body mode, flexible mode deflections, flexible mode rates, unsteady aerodynamic states, actuator deflection and rate states, and wind gust states. Elght states result from the structural modes retained, elght from the two-lag-term set of approximated unsteady aerodynamics, six from the two actuators, and two from the gust mode1. The three outputs are the accelerations at the center of gravity, right wingtip, and left wingtip.

\section{CONTROL LAW DESIGN}

\section{Optimal Controller}

The Iinear quadratic Gaussian (LQG) method is viable for the design of multi-input multioutput controllers. The active control synthesis is based on $L Q G$ theory but is modified to accommodate the high-order model of the aircraft $[5,6]$. The design process involves the following steps state-space model generation; full-state feedback design, estimation of states from avallable measurements, and development of reduced-order controller. 
The state-space model of the aircraft is defined by Eqs. (8) and (9). A full-state feedback control law,

$$
u=-K x
$$

is determined by minimizing a quadratic cost function [7]

$$
J=E\left[\int_{t=0}^{\infty}\left(x^{\top} Q x+u^{\top} R u\right)\right] d t
$$

where $Q$ and $R$ are suitable weighting matrices.

Because direct measurement of all states of an aeroelastic system is not feasible, it is necessary to estrmate states from avallable measurements. A Kalman filter is used for estimation of the states. The estimator dynamics are given by

$$
\dot{\hat{x}}=\left(A-B_{1} K-L_{1} C\right) \hat{x}+L_{1} y
$$

where $L_{1}$ is the Kaiman estimator gain matrıx and $\hat{x}$ is the vector of estimated states. However, systems designed using a Kalman estimator are conditionally stable, have poor gain and phase margins, and have high bandwidth [8]. The input norse procedure of Doyle and Stein [9] can be used to synthesize a robust Kalman estimator. This procedure involves compromising root-mean-square (rms) response activity against robustness. The optimal controller, which is of the same order as the alrcraft model used for synthesis, and the controller output $u_{c}$ are defined as

$$
\begin{aligned}
\dot{\hat{x}} & =(A-B K-L C) \hat{x}+L y \\
u_{C} & =-K \hat{x}
\end{aligned}
$$

where $L$ is the robust Kalman estimator gain matrix.

\section{Practical Controller}

The full-order optimal controller consisting of a robust Kalman estimator together with optimal state feedback gains imposes an unnecessarily large implementation cost. A reduced-order controller that approximates the full-order optimal controller can be found that imposes little degradation in performance [10]. A modal residualization technique [11] can be used to reduce the order of the controller. An attempt is made to approximate the full-order controller with a lower-order approximation while maintaining the desired characteristics of the original controller. A similarity transform $A$ is employed on the full-order controller described by Eqs. (13) and (14) to obtain

$$
\begin{aligned}
\dot{z} & =\Lambda z+T^{-} I_{L y} \\
U_{C} & =-K T z
\end{aligned}
$$

where $T$ is the modal matrix and

$$
\begin{aligned}
\Lambda & =T^{-1} A_{A_{\text {aug }}}{ } \\
A_{\text {aug }} & =\left(A-B_{1} K-L C\right) \\
\hat{x} & =T 2
\end{aligned}
$$

This can be expanded to

$$
\begin{aligned}
& {\left[\begin{array}{l}
\dot{z}_{1} \\
\dot{z}_{2}
\end{array}\right]=\left[\begin{array}{ll}
\Lambda_{1} & 0 \\
0 & \Lambda_{2}
\end{array}\right]\left[\begin{array}{l}
z_{1} \\
z_{2}
\end{array}\right]+\left[\begin{array}{l}
B_{11} \\
B_{21}
\end{array}\right] y} \\
& u_{c}=\left[\begin{array}{ll}
c_{1} & c_{2}
\end{array}\right]\left[\begin{array}{l}
z_{1} \\
z_{2}
\end{array}\right]
\end{aligned}
$$

where $\Lambda_{1}, \Lambda_{2}, B_{11}, B_{21}, C_{1}$, and $C_{2}$ are the matr1ces corresponding to the low- and high-frequency parts of the original system matrices. In the low-frequency portion the dynamics are retained, while in the high-frequency portion only the static terms with zero response time assumed for the dynamics are retained. Setting $\dot{z}_{2}=0$,

$$
z_{2}=-\Lambda_{2}^{-1} B_{21} y
$$

Substituting Eq. (19) into Eq. (18),

$$
u_{c}=C_{1} z_{1}-C_{2}\left(\Lambda_{2}^{-1} B_{21} y\right)
$$

Rewriting the reduced system,

$$
\begin{aligned}
& \dot{z}_{1}=\Lambda_{1} z_{1}+B_{11} y=\tilde{A} z_{1}+\dot{B} y \\
& u_{c}=C_{1} z_{1}-C_{2} \Lambda_{2}^{-1} B_{21} y=\ddot{C} z-\tilde{D y}
\end{aligned}
$$

where

$$
\begin{aligned}
& \tilde{A}=\Lambda_{1} \\
& \tilde{B}=B_{11} \\
& \tilde{C}=C_{1} \\
& \tilde{D}=-C_{2} \Lambda_{2}^{-1} B_{21}
\end{aligned}
$$


The eigenvalues of the reduced system are the eigenvalues retained in the $\Lambda_{1}$ portion. A block diagram of the plant and the reduced-order controller is presented in Fig. 5 .

\section{FLUTTER SUPPRESSION APPLICATION}

The control law synthesized by the method outlined in the previous section was applied to the design of an active flutter suppression controller for an oblique-wing aircraft. A generic $45^{\circ}$-wing-skew structural model was developed to simulate flutter at a subsonic flight condition of Mach 0.70 and an altitude of $3048 \mathrm{~m}$. The unstable eigenvalue parr at this flight condition $(0.50 \pm \mathrm{j} 14.37)$ represents primarily wing bending with some torsion.

The design objective was to stabilize the aircraft without exceeding the specified rms control activity so that saturation would not occur. Based on actuator limitations, the rms deflection of the alleron was 11 mited to $5^{\circ}$ and the deflection rate to $30 \mathrm{deg} / \mathrm{sec}$. In addition to stabilizing the aircraft with low surface activity, it is required that the controller be robust. The controller considered here is multi-input, multioutput: The right and left wing control surfaces are independent of each other because of the unsymmetric nature of the aircraft. Robustness of the multiloop control system is evaluated by using the singular values of the return difference matrix $[12,13,14]$.

\section{Linear Quadratic Controller Design}

A full-order control law, identical to the LQG solution, was obtained first for comparison purposes. Initial values of the weighting matrices $Q$ and $R$ of Eq. (11) were selected as null and identity, respectively [6]. All stable elgenvalues remain unchanged and ali unstable elgenvalues are rotated about the imaginary axis [7]. With the resulting values of the full-state feedback gains, the remaining design process was executed (robust output estimation and controller reduction). Though the rms control activity of the reduced controller was within specified limits, the controller was not very robust. To improve the robustness of the final reduced controller, while still retaining low surface activity, parametric variations of $Q$ and $R$ were performed. A matrix $R$ with values of 50,000 along the diagonal and $a$ positive-definite $Q$ with values of 0.00001 along the diagonal gave satisfactory characteristics. The minimum singular value of the return difference matrix, $\alpha$, for full-state feedback was always $>1$, as shown in Fig. 6 , the rms control values are given in Table 1.

\section{Full-Order Controller}

Because all the states are not avallable for feedback, it is required that all states be estimated so that regulator gains can be used. The controller size is the same as that of the aircraft plant, and will be referred to as the full-order controller.
A Kalman estimator is used to estimate the states. The rms values for the control activity are given in Table 1 . The robustness, as indicated by the minimum singular value plot of Fig. 7, is relatively poor, which is characteristic when using an ordinary Kalman estimator [8]. A design procedure described by Doyle and Stein [9] is used to improve the robustness of the Kalman estimator. This method involves applying extra process noise to the control input of the aircraft during estimator design. Figure 8 shows the minimum singular value plot for the return difference matrix for the estimator designed using the additional noise (robust Kalman estimator). The improved stability margin does increase the rms control activity (as shown in Table 1), but it is still within the specified limits.

\section{Reduced-Order Controller}

The robust Kaiman estimator, together with the optimal feedback gains, constitutes an optimal implementable controller. It is, however, impractical to implement this controller because of the cost involved. The cost of implementation can be reduced by developing low-order approximations to the optimal controller; approximations are referred to as practical or reduced-order controllers. The reduced-order controller must achieve closed-10op stability, have satisfactory control activity, and be robust.

A seventh-order controller was obtalned by using the method of modal residualization. Table 2 shows the elgenvalues of the full-order robust controller and the elgenvalues retalned in the reduced-order controller. Figure 9 shows the step response of the full-order and reduced-order controllers and the extent of degradation in the response due to reduction.

The rms control activity for the reducedorder controller is shown in Table 1 , and Fig. 10 is a plot of minimum singular values for this case. Even though there is some degradation caused by controller order reduction, the rms control activity and the stability margin are considered acceptable.

\section{CONCLUSIONS}

An implementable flutter controller for a $45^{\circ}$-skew oblique-wing alrcraft mathematical model was designed using the LQG design methodology. Kalman estimators produced low stability margins, however, the Doyle-Stein procedure for robust estimator design can be used to improve these margins to acceptable values without excessive surface activity. A modal residualization technique was used to obtain a reduced-order controller that satisfied the performance requirements and can be implemented.

New controllers will be designed as improved models (based on the actual flight configuration) of the oblique wing are made avallable. Actual implementation may require gain scheduling as a function of wing skew as well as other parameters. 


\section{REFERENCES}

1. Houbolt, John C., Steiner, Roy, and Pratt, Kermit G., "Dynamic Response of Airplanes to Atmospheric Turbulance Including Flight Data on Input and Response," NASA TR R-199, 1964.

2. Peele, Ellwood L., and Adams, William M., Jr., "A Digital Program for Calculating the Interaction Between Flexible Structure, Unsteady Aerodynamics and Active Control," NASA TM-80040, 1979.

3. Albano, Edward, and Rodden, Wrlliam P., "A Doublet-Lattice Method for Calculating Lift Distributions on 0scillating Surfaces in Subsonic Flows," AIAA J., vol. 7 , no. 2 , Pp. 279-285, 1969.

4. Tiffany, Sherwood H., and Adams, William M., Jr., "Fitting Aerodynamic Forces in the Laplace Domain: An Application of a Nonlinear Nongradient Technique to Multilevel Constrained Optimization," NASA TM-86317, 1984.

5. Mahesh, J.K., Stone, C.R., Garrard, W.L., and Dunn, H.J., "Control Law Synthesis for Flutter Suppression Using Linear Quadratic Gaussian Theory," J. Guidance Control, vol. 4 , no. 4 , pp. 415-422, 1981.

6. Mukhopadhyay, V., Newsom, J.R., and Abel, I., "Reduced-Order Optimal Feedback Control Law Synthesis for Flutter Suppression," J. Guidance Control, vol. 5, no. 4, pp. 389-395, 1982.
7. Kwakernaak, Hurbert, and Sivan, Raphael, "Linear Optimal Control Systems," WileyInterscience, New York, 1972.

8. Doyle, John C., "Guaranteed Margins for LQG Regulators," IEEE Trans. Automat. Control, vol. AC-23, no. 4, pp. 756-757, Aug. 1979.

9. Doyle, J.C., and Stein, G., "Robustness With Observers," IEEE Trans. Automat. Control, vol. AC-24, no. 4, pp. 607-610, Aug. 1979.

10. Gangsaas, D., Ly, U., and Norman, D.C., "Practical Gust Load Alleviation and Flutter Suppression Control Laws Based on a LQG Methodology," AIAA-81-0021, Jan. 1981.

11. Mahesh, J.K., Stone C.R., Garrard, W.L., and Hausman, P.D., "Active Flutter Control for Flexible Vehicles," NASA CR-159160, 1979.

12. Safonov, Michael G., and Athans, Mrchael, "Gain and Phase Margin for Multiloop LQG Regulators," IEEE Trans. Automat. Control, vol. AC-22, no. 2, pp. 173-178, Apr. 1977.

13. Mukhopadhyay, V., and Newsom, J.R. "Application of Matrix Singular Value Properties for Evaluating Gain and Phase Margins of Multiloop Systems," AIAA-82-1574, Aug. 1982.

14. Ly, Uy-Lo1, "Robustness Analysis of a Mult1loop Flight Control System," AIAA-83-2189, 1983.

Table 1 RMS responses at flutter conditions

\begin{tabular}{|c|c|c|c|c|}
\hline & \multicolumn{2}{|c|}{ Right wing } & \multicolumn{2}{|c|}{ Left wing } \\
\hline & $\delta$, deg & $\dot{\delta}, \mathrm{deg} / \mathrm{sec}$ & $\delta$, deg & $\dot{\delta}$, deg/sec \\
\hline Full-state feedback & 1.58 & 7.91 & 0.28 & 3.58 \\
\hline $\begin{array}{l}\text { Full-order controller } \\
\text { with Kalman estimator }\end{array}$ & 1.58 & 12.58 & 0.41 & 5.64 \\
\hline $\begin{array}{l}\text { Full-order controller } \\
\text { with robust Kalman } \\
\text { estimator }\end{array}$ & 2.06 & 11.21 & 0.41 & 5.02 \\
\hline $\begin{array}{l}\text { Reduced-order } \\
\text { controller }\end{array}$ & 1.51 & 10.04 & 0.41 & 4.90 \\
\hline
\end{tabular}


Table 2 Full-order and reduced-order controller eigenvalues

\begin{tabular}{cc}
\hline $\begin{array}{c}\text { Full-order } \\
\text { controller } \\
\text { e1genvalues }\end{array}$ & \multicolumn{1}{c}{$\begin{array}{l}\text { Reduced-order } \\
\text { controller } \\
\text { elgenvalues }\end{array}$} \\
\hline$-0.2531+0.00001$ & $-0.2531+0.00001$ \\
$-0.4578+0.08451$ & $-0.4578+0.08451$ \\
$-0.4578-0.08451$ & $-0.4578-0.08451$ \\
$-6.3566+0.00001$ & \\
$-2.5815+6.36171$ & $-2.5815+6.36171$ \\
$-2.5815-6.36171$ & $-2.5815-6.36171$ \\
$-0.3773+13.11041$ & $-0.3773+13.11041$ \\
$-0.3773-13.11041$ & $-0.3773-13.11041$ \\
$-3.4330+15.36501$ & \\
$-3.4330-15.36501$ & \\
$-20.0399+0.00001$ & \\
$-28.5469+9.70161$ & \\
$-28.5469-9.70161$ & \\
$-36.0773+0.32611$ & \\
$-36.0773-0.32611$ & \\
$-37.0844+2.44341$ & \\
$-37.0844-2.44341$ & \\
$-40.1968+1.37961$ & \\
$-40.1968-1.37961$ & \\
$-36.1567+37.22251$ & \\
$-36.1567-37.22251$ & \\
$-53.6588+0.00001$ & \\
$-34.5946+44.06571$ & \\
$-34.5946-44.06571$ & \\
\hline- &
\end{tabular}

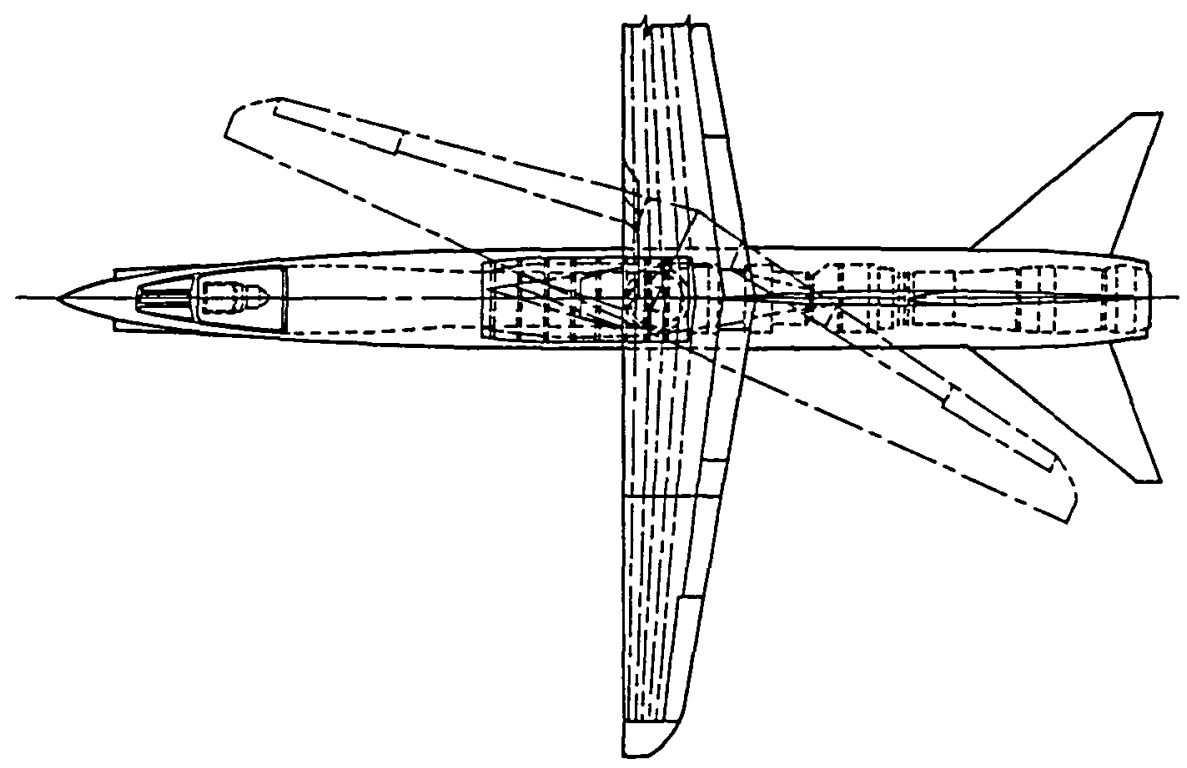

Fig. 1 Oblique-wing configuration. 


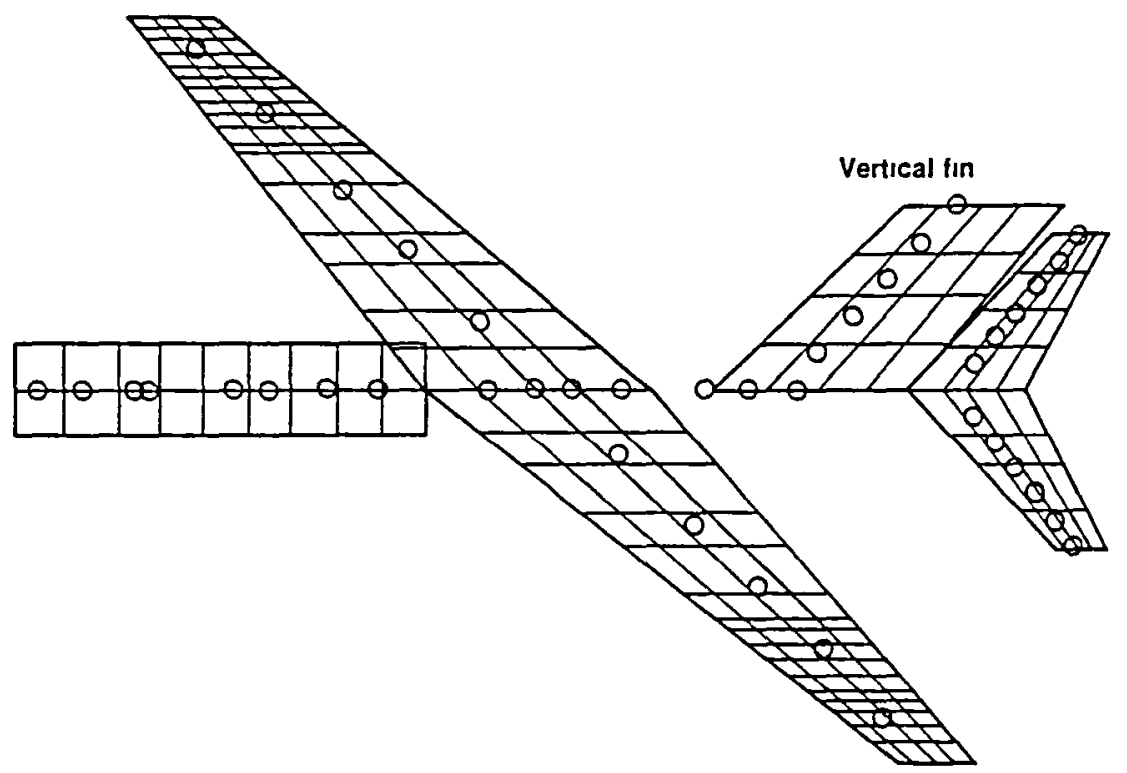

Eig. 2 Generic model (aero panels and node points). Vertical fin shown in $X-Y$ plane.
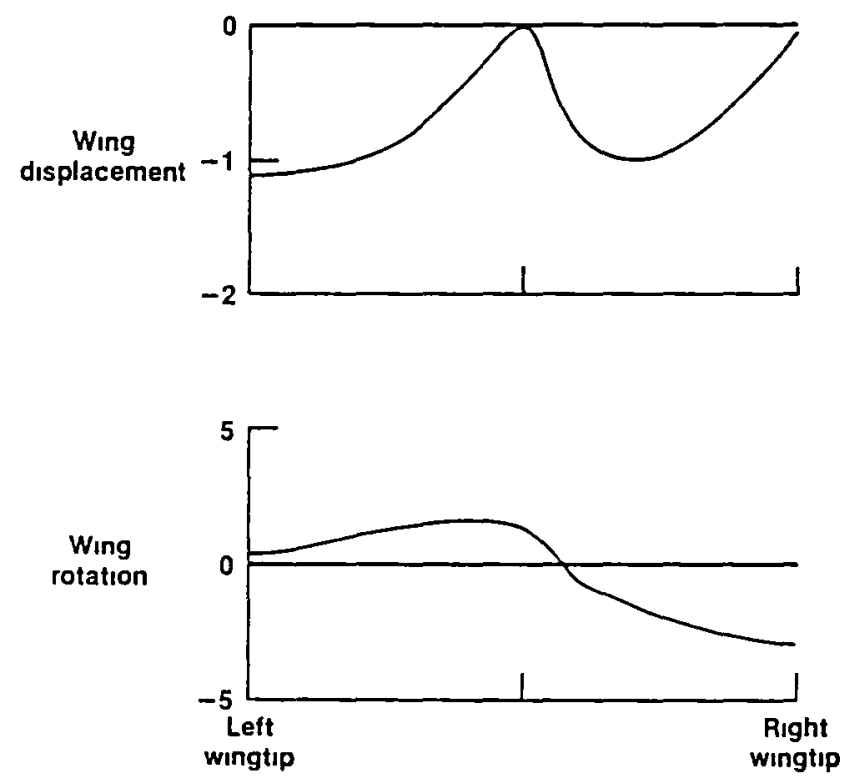

Fig. 3 In-vacuun flutter mode shape characteristrcs at $2.239 \mathrm{~Hz}, 45^{\circ}$ skew.

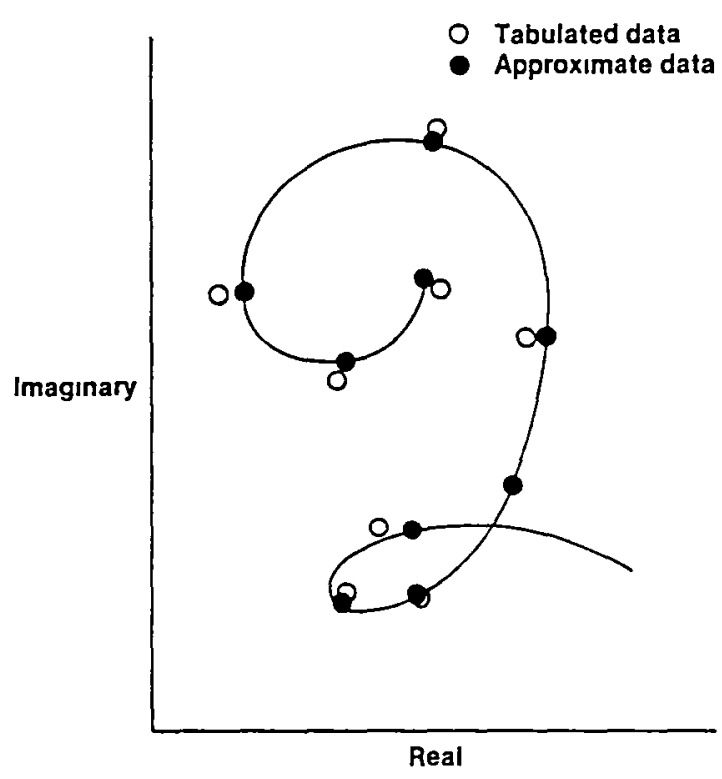

Fig. 4 Unsteady aerodynames compamson. 


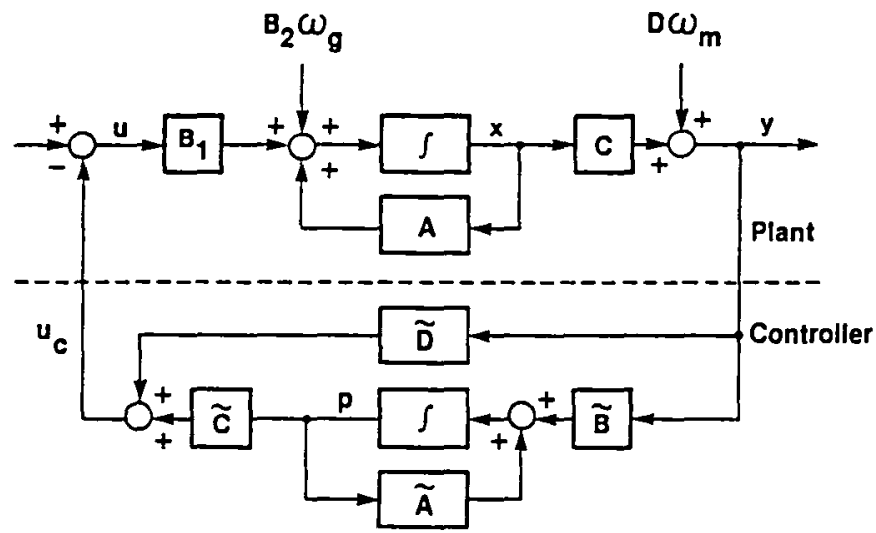

Fig. 5 Closed-loop system with reduced-order controller.

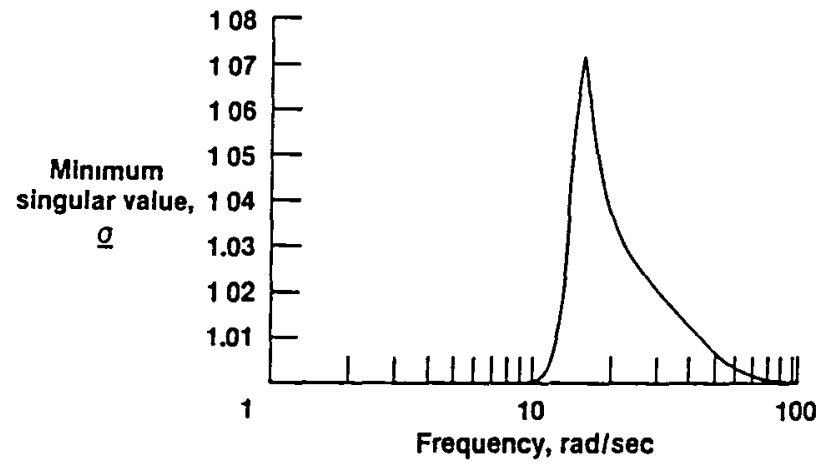

Fig. 6 Minimum singular values for full-state feedback.

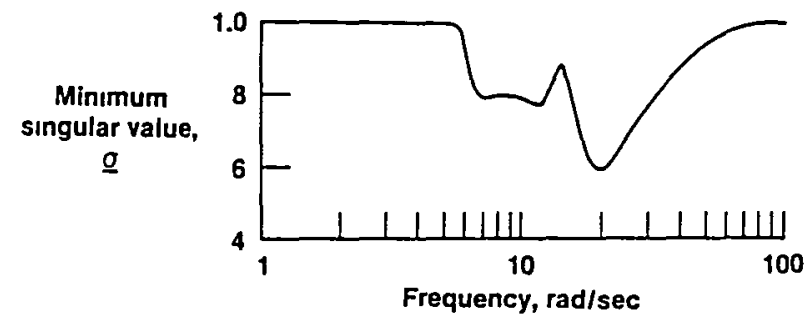

Fig. 8 Minimum singular values for full-order controlier with robust Kalman estimator.

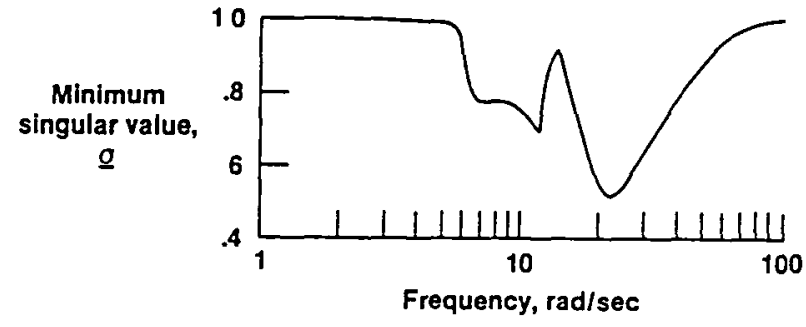

Fig. 7 Minzmum stngular values for full-order controller with Kalman estimator.

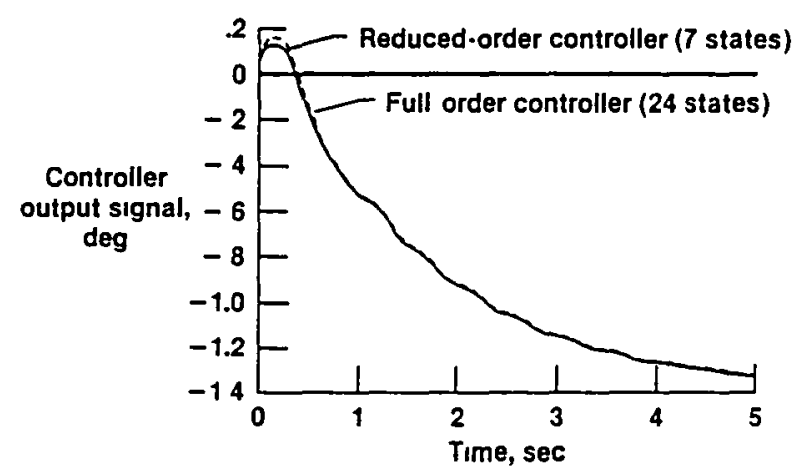

Fig. 9 Step response comparzoon of full-order controller and reduced-order controller.

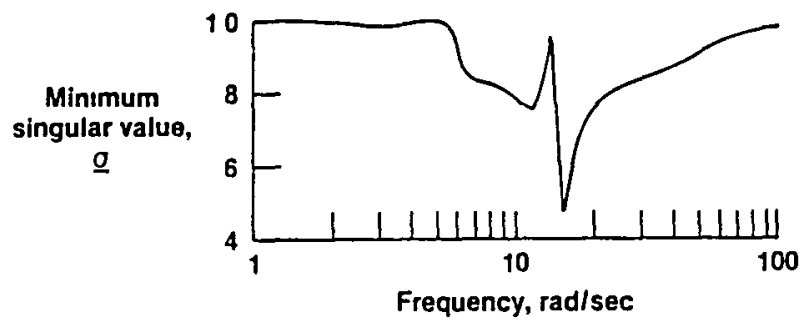

F2g. 10 Minimum singular values for reducedorder controller. 


\begin{tabular}{|c|c|c|c|}
\hline $\begin{array}{l}1 \text { Report No } \\
\text { NASA TM-86808 }\end{array}$ & 2 Government Accession No & 3. Recipient's Ca & \\
\hline $\begin{array}{l}4 \text { Title and Subtitle } \\
\text { AEROELASTIC CONTROL OF }\end{array}$ & NG AIRCRAFT & $\begin{array}{c}5 \text { Report Date } \\
\text { June } 1986\end{array}$ & 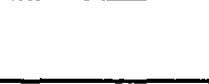 \\
\hline & & 6 Performing Ors & ation Code \\
\hline $\begin{array}{l}\text { 7. Author(s) } \\
\text { John J. Burken, Gurbux }\end{array}$ & nd Glenn B. Gilyard & $\begin{array}{l}\text { 8. Performing Org } \\
\mathrm{H}-1346\end{array}$ & ation Report No \\
\hline & & 10 Work Unit No & \\
\hline 9 Performing Organızation Name a & & RTOP 533-02- & \\
\hline $\begin{array}{l}\text { NASA Ames Research Cent } \\
\text { Dryden Flight Research } \\
\text { P.0. Box } 273 \\
\text { Edwards. CA } 93523-5000\end{array}$ & & 11 Contract or $\mathrm{Gr}$ & \\
\hline 12. Sponsoring Agency Name and & & $\begin{array}{l}13 \text { Type of Repor } \\
\text { Technical Me }\end{array}$ & $\begin{array}{l}\text { d Period Covered } \\
\text { andum }\end{array}$ \\
\hline $\begin{array}{l}\text { National Aeronautics and } \\
\text { Washington, D.C. } 20546\end{array}$ & ministration & 14 Sponsoring $\mathrm{Ag}$ & Code \\
\hline $\begin{array}{l}15 \text { Supplementary Notes } \\
\text { Prepared for presentat } 10 \\
\text { Seattle, Washington, Jur } \\
\text { *Western Michigan Univer }\end{array}$ & $\begin{array}{l}1986 \text { American Control Conf } \\
1986 . \\
\text { amazoo, Michigan }\end{array}$ & & \\
\hline $\begin{array}{l}\text { T } \\
\text { desic } \\
\text { capat } \\
\text { skew- } \\
\text { a fly } \\
\text { this } \\
\text { An ac } \\
\text { linea } \\
\text { modal } \\
\text { contr }\end{array}$ & $\begin{array}{l}\text { avy and NASA are currently } \\
\text { elopment of an unsymmetric } \\
\text { wing sweep and flight at } \\
\text { raft model was developed f } \\
\text { tion of Mach } 0.70 \text { and } 3048 \\
\text { ndition the aircraft has } \\
\text { ementable control law was } \\
\text { ic Gaussian design technig } \\
\text { ization was used to reduce } \\
\text { d for flutter suppression. }\end{array}$ & $\begin{array}{l}\text { in the } \\
\text { aircraft } \\
\text { A generic } \\
\text { g skew at } \\
\text { e. At } \\
\text { ter mode. } \\
\text { using the } \\
\text { hod of } \\
\text { of the }\end{array}$ & \\
\hline $\begin{array}{l}17 \text { Key Words (Suggested by Auth } \\
\text { Active flutter suppress } 1 \\
\text { Obl 1que-wing aircraft } \\
\text { Robust reduced-order con }\end{array}$ & $\begin{array}{l}18 \text { Distribe } \\
\text { Unclass }\end{array}$ & $\begin{array}{l}\text { Iimited } \\
\text { STAR categor }\end{array}$ & \\
\hline $\begin{array}{l}19 \text { Security Classif (of this report) } \\
\text { Unclassified }\end{array}$ & $\begin{array}{l}20 \text { Security Classif (of this pagel } \\
\text { Unclassified }\end{array}$ & $\begin{array}{c}21 \text { No of Pages } \\
10\end{array}$ & $\begin{array}{l}22 \text { Price } \\
\text { A02 }\end{array}$ \\
\hline
\end{tabular}

For sale by the National Technical Information Service, Springfield, Virginia 22161. 
End of Document 